\title{
Finding new uses for thalidomide
}

Thalidomide is making a comeback. Some 30 years after it became known that the drug - a potent anti-inflammatory and immunosuppressive agent - causes birth defects, thalidomide is showing promise as an experimental treatment for one of the late-stage symptoms of AIDS. Midtrial results released in late October from a phase II, placebo-controlled study showed the drug provided a safe and effective treatment for the painful mouth ulcers (oral aphthous ulcers) in patients with HIV.

In light of the recent data, the placebo arm of the study for this indication has now closed and all patients (current and future enrollees) will now be given the opportunity to receive the drug on an open-label' basis. The interim analysis of the data showed that mouth ulcers healed in 61 percent ( 14 out of 23 ) of patients who received thalidomide, compared with only 4.5 percent ( 1 of 22 ) in the control group.

The study, which is in two parts, is supported by the National Institute of Allergy and Infectious Diseases (NIAID) and conducted through NIAID's AIDS Clinical Trials Group. Part two is testing thalidomide as a treatment for oesophageal ulcers in AIDS patients.

First introduced in the late 1950s, thalidomide was initially marketed as a sedative and 'safe' alternative to barbiturates. Only later was it prescribed as a treatment for morning sickness. Its use for these indications was discontinued in the 1960 s after it became known that the drug caused serious birth defects. It was never approved in the United States (serendipitously, reports of birth defects in infants in England and Germany appeared before the drug was approved here). Unofficially, however, some AIDS patients are now taking the drug, which can be obtained through underground 'buyers' clubs', to treat primary AIDS, ulcers and HIV-associated cachexia, or wasting. Thalidomide is also in use in Brazil for the treatment of erythema nodosum leprosum, a complication of leprosy, and in France for lupus.

Although thalidomide carries a high risk of causing birth defects in infants born to women taking the drug, the effects are well-documented. Women of childbearing age did participate in the study. "We felt strongly that women should be allowed equal access to a potentially beneficial therapy," says Jeffrey M. Jacobson of the Bronx Veterans Affairs Medical Center and Mt Sinai School of Medicine in New York,

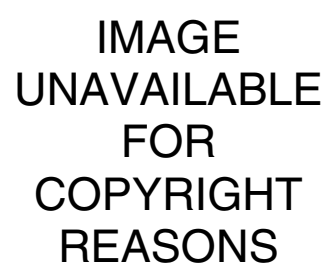

Does thalidomide have a future?

who is also chair of the study. However, a series of safety measures were taken to minimize the risks. Women were asked either to refrain from having sexual intercourse or were asked to use three methods of contraception at once - two barrier, one hormonal. Periodic pregnancy tests were also given.

The scientific literature is "replete with

anecdotal studies" indicating the potential of thalidomide to act against a range of previously untreatable or life-threatening diseases, says Peter Andrulis, president and chief executive officer of Andrulis Pharmaceuticals of Beltsville, Maryland, the company supplying the drug in the ulcer study. (This is one of two US companies hoping to find new uses for thalidomide. Celgene of Warren, New Jersey, is testing it as a treatment for wasting.) It is somewhat ironic, Andrulis says, that it is because thalidomide may have beneficial effects in this subcategory of indications that the US Food and Drug Administration (the agency that originally kept it off the market) will now be able to evaluate it on an 'accelerated review' basis. DIANE GERSHON

\section{AIDS summit approaches}

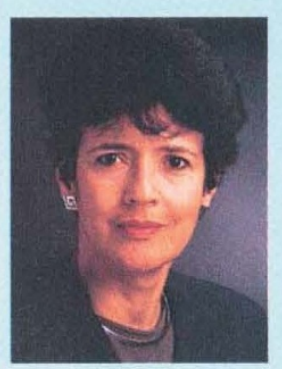

Patricia Fleming, director of the White House Office of AIDS Policy.
Two hundred experts on different aspects of AIDS are travelling to Washington, DC, on 6 December to meet with US President Bill Clinton in the first 'White House Conference on HIV and AIDS'. This summit was called by Clinton in response to recommendations issued by his newly formed President's Advisory Council on HIV and AIDS. Despite its high profile, organizers of the summit already find themselves fending off some of the criticisms that have met other Clinton administration AIDS-related initiatives.

One of these is the sheer scope of the task set for the one-day meeting: Participants "will discuss the latest trends in the AIDS epidemic, epidemiological surveys and studies of the AIDS epidemic itself, and the central issues of AIDS research, prevention, care and discrimination, among other things," according to Michael McCurry, the president's press secretary. Despite criticism of biting off more than can reasonably be chewed, this is believed to be 'doable' by Patricia Fleming and other meeting organizers at the White House Office of AIDS Policy. The meeting will be "very similar" to previous White House conferences on other topics, according to Richard Sorian, director of public relations for the AIDS policy office. "A set of working groups on different topics will meet separately and form recommendations for action," he says. These will be presented at an afternoon plenary session, followed by open discussion among all participants.

Extremely high expectations are another problem. "The most misunderstood thing about this conference is that it's not the Manhattan Project," says R. Scott Hitt, chair of the Advisory Council. "It isn't supposed to come up with answers. Rather, we are getting all these people together to discuss with the President and the nation the state of AIDS in this country." Nevertheless, some participants are hoping that the summit will lead to action. "We are hoping for concrete achievements and an end to rhetoric," says Michael Isbell, associate executive director of the Gay Men's Health Crisis in New York, and a summit invitee. Isbell cites protection for people with AIDS under Medicaid, a lifting of the ban on needle exchanges and the elimination of restrictions on the contents of literature (such as safe-sex handouts) as realistic possibilities for action.

The selection of the final 200 attendees (of the estimated 1,200 names submitted) were still largely unknown as Nature Medicine went to press, but an anonymous White House source says there are "quite a few surprises, especially at who was not invited." However, the summit will ultimately be judged not by who attends, but by what happens as a result.

FINTAN R. STEELE 